Keywords: SARS-CoV-2, COVID-19, coronavirus, pandemic, food, hygiene

\section{systems}

\title{
COVID-19 pandemic and its implications on food
}

Hilal A Makroo ${ }^{1}$, Darakshan Majid ${ }^{1}$, Mushtaq A Siddiqi ${ }^{2}$, Ralf Greiner ${ }^{3^{*}}$ and B.N.Dar ${ }^{*}$

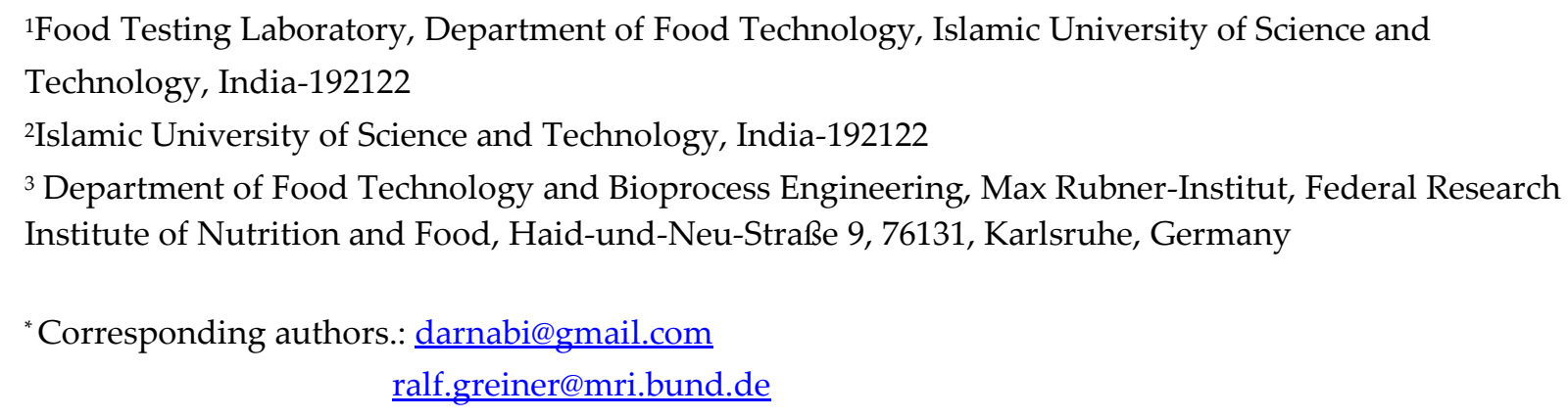

Abstract: The outbreak of COVID-19 started in mainland China and has rapidly spread to more than 200 countries and territories around the world (WHO, 2020). The new coronavirus is a respiratory virus and its transmission is known to occur by upper respiratory secretions, including airborne droplets after coughing or sneezing. There is no evidence to support the role of food in the transmission of COVID-19. However, sharing food in public places is not encouraged. Furthermore, standard operating procedures of food safety like thorough washing, avoid cross contamination, keeping raw and cooked foods separated, refrigeration and heating are highly suggested. The pandemic has dramatically increased food insecurity across the countries and threatens the food security and nutrition of millions of people. The review presents information about SARS-CoV-2 with respect to food, including a brief history of coronavirus, its classification and transmission. It further presents the role of food as a carrier of the virus, which looks unlikely so far but cannot be fully ruled out, food contamination and handling followed by prevention and safety measures as per the standard guidelines, and conclusive remarks. 


\section{Introduction}

The family Coronaviridae encompasses a broad spectrum of animal and human diseases causing viruses, all characterized by a distinctive morphology [1]. Virions are enveloped in self-assembled microcapsules and are spherical (coronaviruses) in shape. Each particle is enclosed by a fringe or "corona" representing the bulbous distal ends of embedded envelope glycoproteins (Figure 1). The family consists of two subfamilies, Coronavirinae and Torovirinae, the latter being associated with viruses causing mainly enteric infections of horses, cattle, pigs, cats, and goats [2]. The Coronavirinae subfamily is divided into four genera. The genus alphacoronavirus includes the human virus HCoV-229E, and HCoV-NL63, and many animal viruses. The genus betacoronavirus comprises the mouse hepatitis virus (MHV), the human viruses HCoV-OC43, SARS-HCoV, HCoV-HKU1, the severe acute respiratory syndrome coronavirus (SARS) related coronavirus, the Middle Eastern respiratory syndrome (MERS) coronavirus, and many animal coronaviruses. The genus gammacoronavirus includes viruses of cetaceans (whales) and birds, and the genus delta coronavirus viruses isolated from pigs and birds. Coronavirus disease was first described in 1931, with the first coronavirus (HCoV-229E) isolated from humans in 1965 [3]. After 2005, several novel coronaviruses have been isolated from bats, and there is an indication that human respiratory coronaviruses, SARS coronavirus, and MERS coronavirus, may each have originally emerged from ancestral bat viruses.

The coronavirus disease (COVID-19) started from Wuhan, China, from late December 2019 on, probably linked to a seafood market [4]. However, there is no confirmation so far that the origin of SARS-CoV-2 was from the indicated market. Several studies suggested that bats may be the possible reservoir of SARS-CoV-2 [5]. Direct contact with intermediate host animals or consumption of wild animals was supposed to be the main route of SARS-CoV-2 transmission to humans. However, the source(s) and transmission route(s) of SARS-CoV-2 remain indistinct [4]. Due to the minimal to no pre-existing immunity in the human population against the new coronavirus, it is now spreading rapidly and exponentially worldwide [6]. The disease has now been labeled as a pandemic due to its worldwide spread and impacts. The world track of Covid-19 is depicted in Figure 2 and the data of the Covid-19 reported cases and deaths globally is shown as Figure 3. 


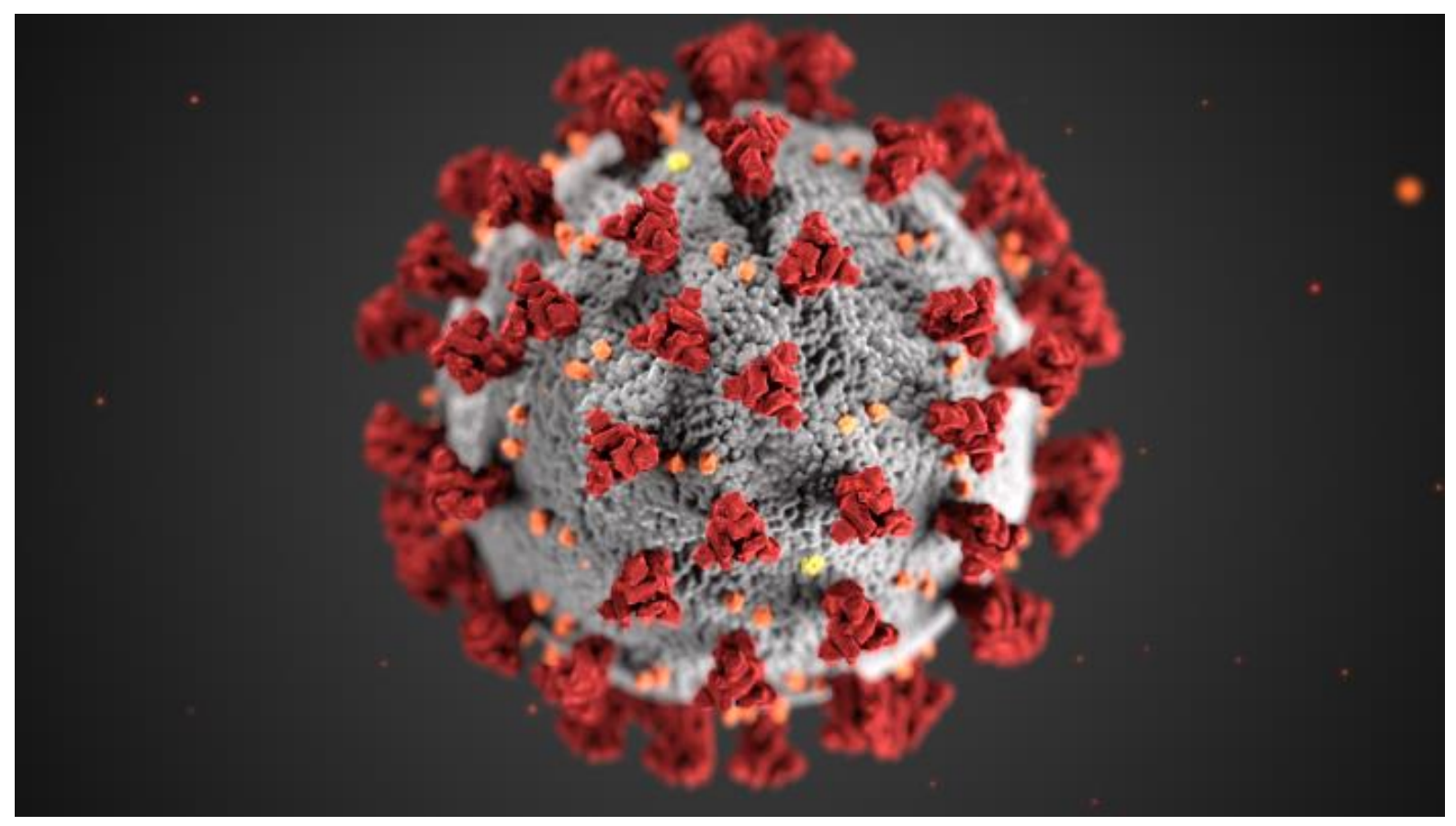

Figure 1 This illustration, created at the Centers for Disease Control and Prevention (CDC), reveals ultrastructural morphology exhibited by coronaviruses. Note the spikes that adorn the outer surface of the virus, which impart the look of a corona surrounding the virion, when viewed electron microscopically. A novel coronavirus, named Severe Acute Respiratory Syndrome coronavirus 2 (SARS-CoV-2), was identified as the cause of an outbreak of respiratory illness first detected in Wuhan, China in 2019. The illness caused by this virus has been named coronavirus disease 2019 (COVID-19). Contributed from the CDC, Alissa Eckert, MS; Dan Higgins, MAM (Public Domain)

According to the WHO (2020) [7], the majority of people that have COVID-19 (about 80\%) recuperate without needing special treatment. However, one out of every six people who get COVID-19 becomes seriously ill and develops difficulties in breathing. People who are immunocompromised, older, and/or have upper respiratory or heart conditions are noted as being "high-risk" and may be more likely to develop serious symptoms and need medical attention. As COVID-19 spreads mainly through human-tohuman contact, therefore, the first line of protection in the transmission is minimizing gathering in groups of all sizes. In particular, this means staying away from large groups and crowds, avoiding being in close contact (within three to six feet) with people who could be sick and avoiding gathering with people who are at high risk for infection. Infected individuals should stay away from others as much as possible, cover their mouth and nose when coughing or sneezing, and should also keep their hands clean to help avoid spreading the virus to others [6]. The dispersal of disease is significantly associated with respiratory expelling via cough, sneeze, or other methods of releasing respiratory droplets that can carry the virus from an infected individual to uninfected individuals who breathe in droplets and can become ill. There is no evidence of direct contamination or transmission of the diseases by food, however, that doesn't allow us to completely ignore its spread by consuming foods served on contaminated surfaces or 
72 chances of transmission during handling or sharing food with an already contaminated person.

73 Therefore, the present article describes the relation of SARS-CoV-2 with food handling, safety, and 74 security.

75

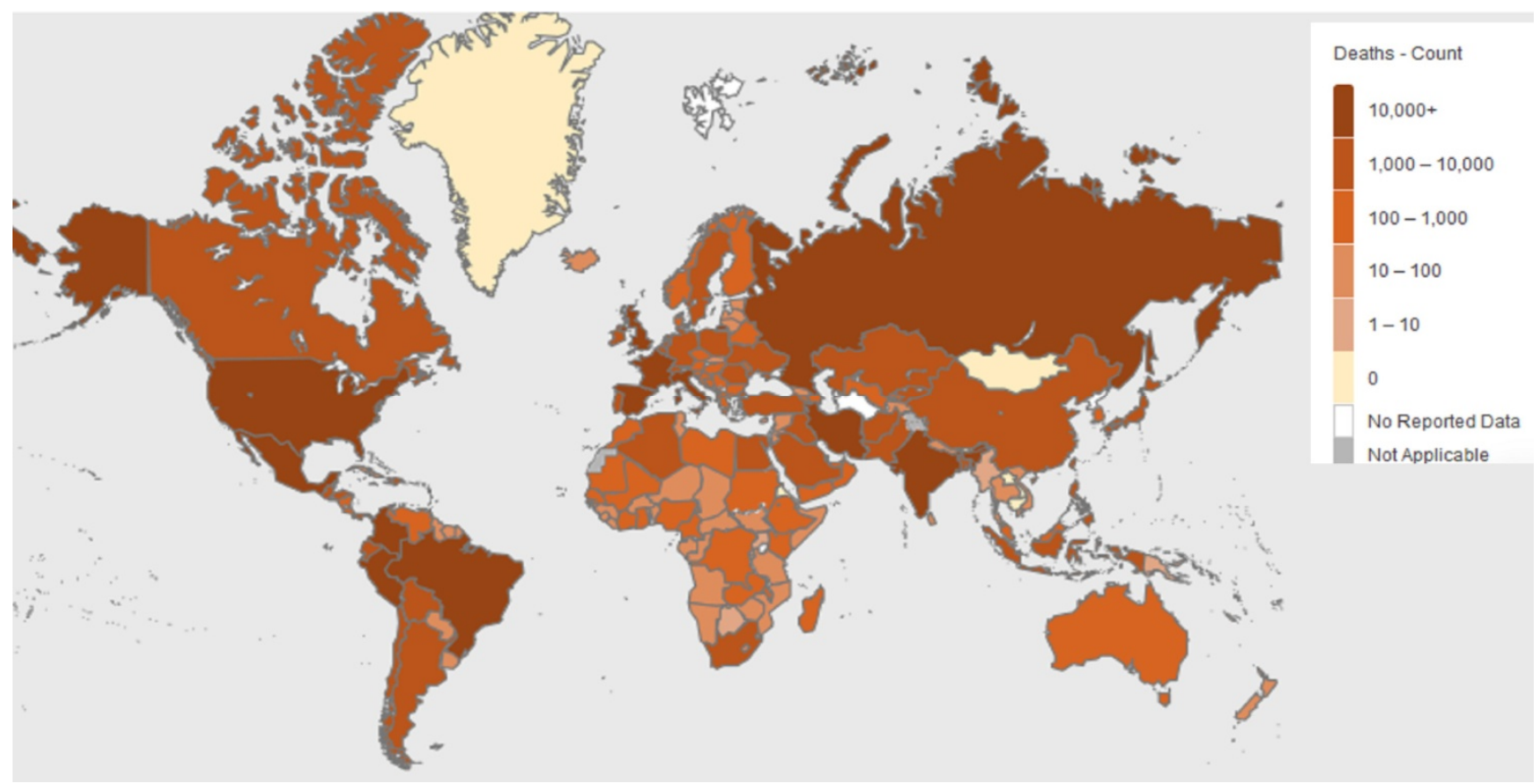

Figure 2 The track of Covid-19 cases world wide as on 07 August 2020 (Source: WHO https://covid19.who.int/) 76 
78

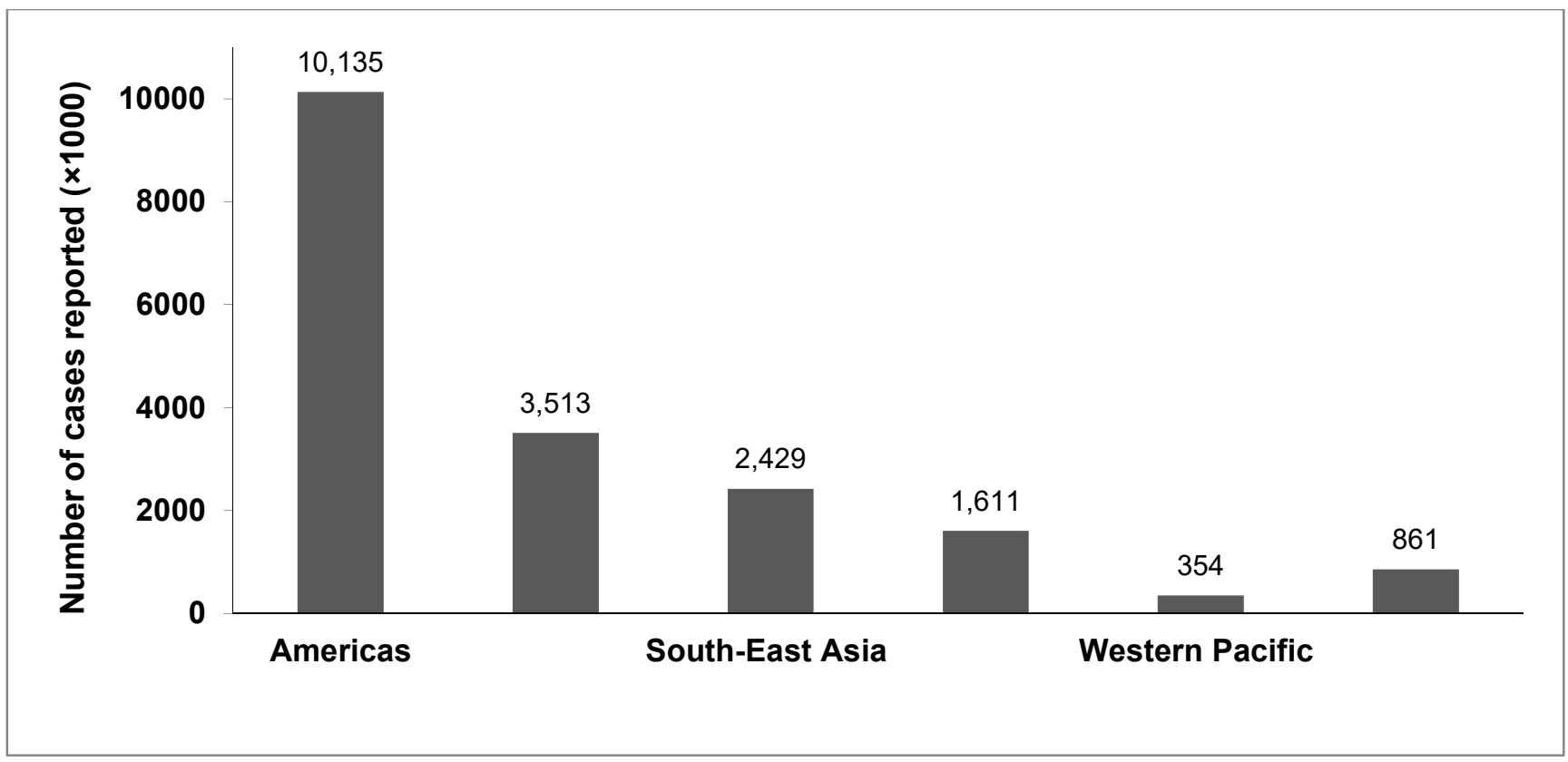

(a)

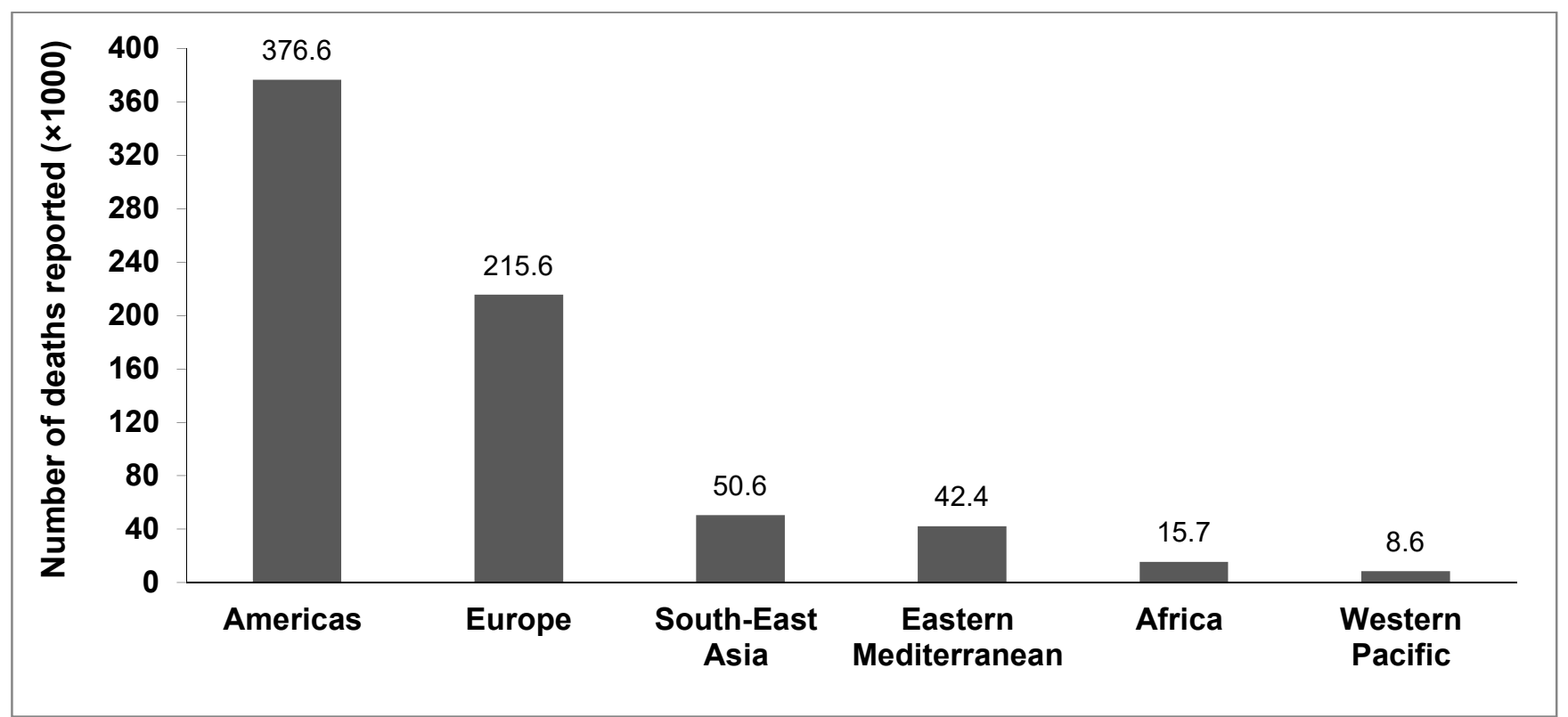

(b)

Figure 3 Number of cases (a) and deaths reported as on 07 August 2020 (WHO Coronavirus disease (COVID-2019) situation report 200) https://www.who.int/emergencies/diseases/novel-coronavirus-2019/situation-reports 79 
80

81

82

83

84

85

86

87

88

89

90

91

92

93

94

95

96

97

98

99

100

101

102

103

104

105

106

107

108

109

110

111

112

113

\section{Food as a carrier of Viruses}

The primary reason for various severe zoonoses including many viral diseases originated from bats has been found in human animal interactions. However, the link between such interactions and the spillover risk is poorly understood as animal-to-human spillover events leading to emerging diseases are rarely observed or clinically examined [8]. Viruses are now considered as the most common cause of foodborne illness but are rarely diagnosed due to the limited analytical and diagnostic tools available. The transmission of food borne viruses becomes a serious concern. Viruses like the highly pathogenic avian influenza (HPAI) virus, the Nipah virus, and the SARS-CoV which causes respiratory illness spread through the fecal and oral route, unlike other viruses. The large outbreaks may be the result of a combination of several transmission routes (via food, water, and feces) and thereafter violently by direct contact from person to person (WHO, 2008) [9]. These viruses could contaminate a range of food products at different stages of processing. Several foods receive less or no heat treatments which are highly associated with foodborne viral outbreaks [10]. Researchers have examined a number of foods for the presence of viruses like Human Rotavirus, Astrovirus, Hepatitis E virus (HEV), Sapovirus, Adenovirus, Enterovirus, Aichi virus and Coronaviruses (WHO, 2008) [9]. Especially minimally processed foods or food items consumed raw/uncooked were identified to carry a high number of these viruses [11].

Although not considered as the main reason for virus spread, it is possible that a person can get COVID-19 by touching a surface or object that is already contaminated with the virus followed by touching their mouth, nose, or possibly their eyes facilitates its spread [12]. Up to now, there is no literature confirming the transmission of SARS-CoV-2 through the ingestion of virus-contaminated food. But, we cannot fully rule out the possibilities as there is no conclusive study reported in this regard. Other than the primary route of infection and/or by person-to-person contact, this route could be significantly crucial. Infected food handlers and harboring zoonotic viruses have been previously identified as major transmission routes [13]. The virus may get attached to the food material due to misshandling during processing, transportation, storage, or even preparation, and depending upon the viral load it may cause disease if it enters through the proper route. There is a possibility of the infection being transmitted through food by a contaminated person who has not followed standard operating procedures (SOPs) of handling and sanitation for example through food sold and consumed at a low hygienic standard such as some street foods in low-income countries. Processing and selling the foods under such conditions increase the chances and concentration of microbial (viral) load, which in turn may lead to a higher probability of the infection. Fresh foods may also be similarly exposed to SARS-CoV-2 before being frozen, in this case, the transmission may happen. For instance, it is known that MERS and SARS$\mathrm{CoV}-1$ can remain infectious for up to 2 years in a frozen state [14]. Similarly, openly sold food items such as bakery products may also get easily contaminated with the virus through contaminated persons by air 
114 droplets. There are high chances of cross-contamination of foods after processing. The compromise with 115 food handling management may cause contamination at any step of the food supply chain. These viruses

116

117

118

119

120

121

122

123

124

125

126

127

128

129

130

131

132

133

134

135

136

137

138

139

140

141

142

143

144

145

146

Since the available literature about infection with the SARS-CoV-2 via food is very limited, the potential role of foods in spreading this virus is being studied extensively by the International Food Safety Authorities Network (INFOSAN) as well as national food safety authorities. For example, investigations are being conducted to check the viability and survival time of SARS-CoV-2 in different foods [7].

\section{Prevention and safety measures}

The indirect transmission through contact with contaminated surfaces and devices is also highly likely as reported for other members of the coronavirus family; however, the potential to cause the disease depends on the concentration of the virus [16]. The data for how long the virus can remain viable on food is limited, but in general, viral loads remain more stable on non-porous surfaces like metal and plastic and break down faster on organic surfaces like cardboard.

Although the detection of the viability of viruses on different surfaces depends upon various factors such as virus concentration, the presence of substances which can interfere with analysis procedures sampling, inoculation, method of detection, experimental condition, physical properties of the surface (viruses can be trapped within the matrix, especially if the surface is porous), etc [17]. The SARS CoV-2 has been reported to remain viable in air for almost 3 hours, whereas the viability on plastic and stainless steel surfaces was up to 72 hours and it remained undetected on the copper surface and cardboard after a few hours and twenty-four hours, respectively [18]. However, in addition to the viability, the viral load on the surface of the material will be the deciding factor for infection to occur. Therefore, the culinary surfaces, equipment and utensils need to be cleaned properly. The proper and sufficient contact of the detergent with the surfaces is very crucial for efficient sanitization. Warm to hot water should be preferred for the sanitization and cleaning pertaining to the outer lipid layer in the structure of the SARS CoV-2 cell [19, 20].

The viruses are made up of material surrounded by a coating of proteins and fat or they are selfassembled nano-particles in which the weakest link is the lipid (fatty) bi-layer [19]. The basic structure of the SARS CoV-2 and the working mechanism of the soap/detergent make hand washing by soap the best way to prevent the spread of SARS CoV-2. Soap destroys viruses because when viruses interact with soap, its fat coating gets cleaved out by the soap molecules Figure 4 [21]. Ethanol and other alcohols 
147 interact with lipid membranes and effectively dissolve the lipid membranes. Alcohols are highly 148 lipophilic and dissolve the lipid membrane of the virus but at a fairly higher concentration $(>60 \%)$. 149 However, vodka or whiskey contains around $40 \%$ ethanol and will not dissolve the virus as quickly. 150 Therefore, soap is easily accessible and a cheap source for surface decontamination and personal hygiene 151 of the working staff [19].

152 In general, to prevent food borne illness FDA suggests to follow the four key steps which include clean, 153 separate, cook, and chill. In the present scenario of Covid-19, we should be extra careful to prevent the 154 contamination from surfaces, packaging, utensils, or equipment, etc. while preparing or processing the 155 food as its mode of transmission and viability is not fully understood. There should be a proper 156 examination of the person working in any industry for any chance of symptoms or their contact with an 157 infected person. Good hygiene and sanitation are important to avoid cross-contamination between raw or 158 undercooked foods and cooked or ready to eat foods in the kitchen.

Raw or minimally processed foods and cooked food should be kept separate and utensils, knives, 160 and chopping boards should be cleaned regularly while dealing with raw and minimally processed foods 161 [11]. However, using good quality gloves while handling raw and minimally processed foods would be 162 more appropriate. The practice of consumption of undercooked or raw meat, fish, and seafood should be 163 avoided and the sufficient washing and cleaning of the foods meant to be consumed raw such as fresh 164 fruits or salad need to be practised. While handling the raw meat, raw milk, or raw animal organs it is 165 advised that it should be handled with care to avoid cross-contamination [9]. Exposing the SARS-CoV-2 166 to a temperature of $56-67^{\circ} \mathrm{C}$ for $60-90 \mathrm{~min}$ has been reported to cause its inactivation [22]. Therefore, in 167 the case of hot foods, the virus would likely be killed by the high temperatures applied during cooking as 168 it is believed that higher temperatures can facilitate the destruction of SARS-COV-2 and its stability on 169 the surfaces [23]. This may not be the case with fresh fruits and vegetables and uncooked foods like salads or sandwiches. 


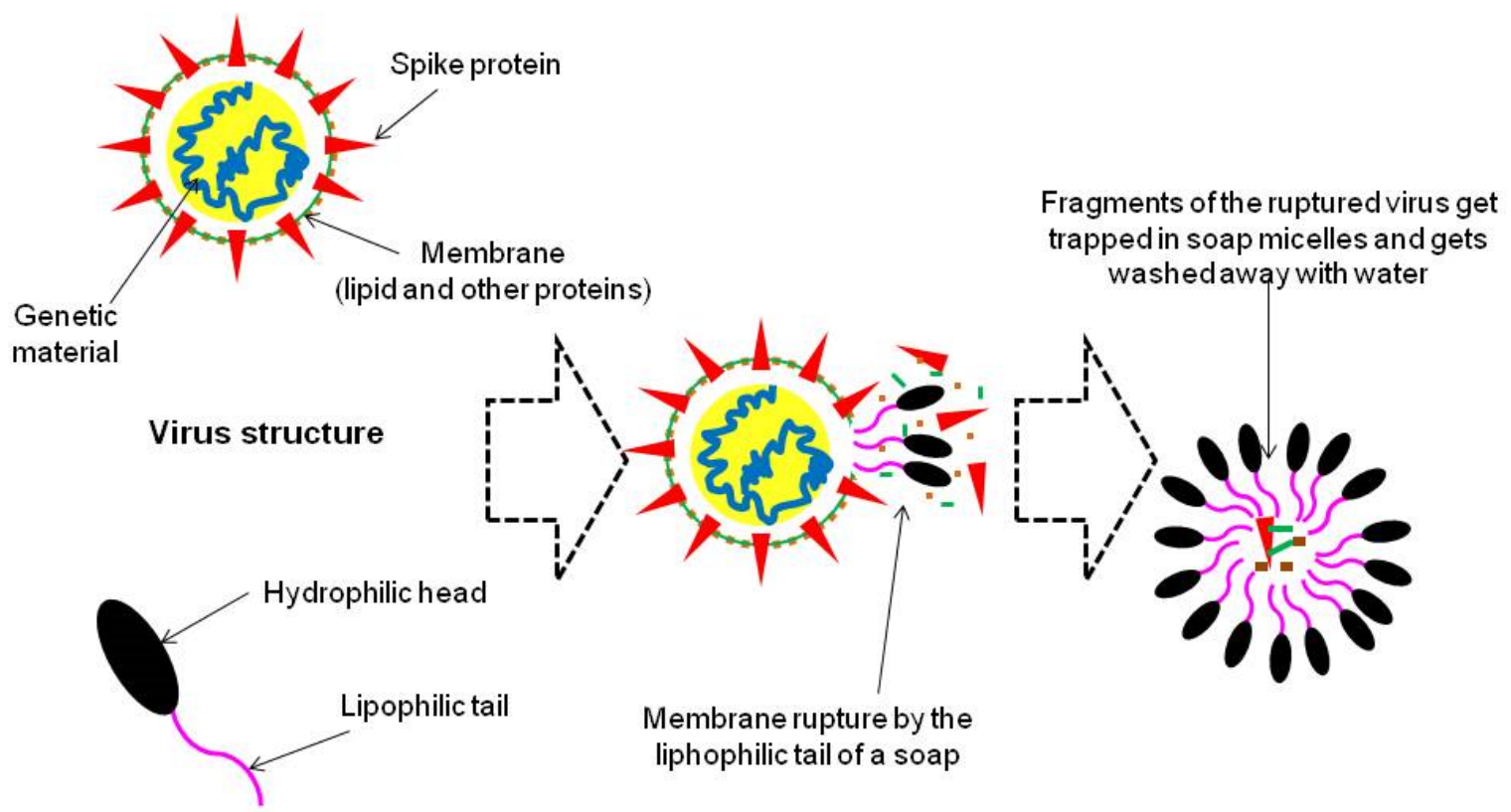

Soap molecule

Figure 4 The mechanism disruption of virus structure by of soap molecule

In this connection strengthening of sanitation and hygiene is recommended by the health-related agencies globally. The recommendation includes drinking safe water as some studies have reported the survival of SARS-CoV-2 in water or wastewater sources for days or weeks [24, 25], using separate meal systems, regular hand-washing, disinfecting toilets and preventing water and food contamination from the stool as there are indications that SARS-CoV-2 may cause intestinal infection and be present in the stool $[26,27]$. While preparing food at home, raw food should be handled and cleaned properly. The best way to prevent its transmission through food is to make sure that no virus-carrying personnel come in contact with the food, food processing premises, or working staff. Therefore, proper testing and scanning of working staff would be one of the major precautionary measures to tackle the situation. Hands must be washed thoroughly with soap in between handling or touching raw and cooked food, and thorough cooking and proper handling of meat products must be taken sincerely. As an added precaution, if you have suspected symptoms of respiratory illness you should avoid preparing food for other people and seek medical attention [7].

\section{Nutrition and COVID-19}

The fight against Covid-19 is not limited to the use of masks and sanitation only, but the immune system of the human body also needs to be strong. Old and aged people are most susceptible to the Covid-19 [28], probably due to their weak immunity. A strong human immune system is believed to be responsible for the protection against various bacteria, viruses, and protozoan parasites. The immune system can be boosted by proper sleep, reduction in the stress level, moderate exercise, and healthy food [29, 30, 31]. 
192 The protein-rich diet may boost the antibody generation in humans thus help in countering the SARS193 CoV-2 infection. A diet rich in milk, honey, fruits, and vegetables such as citrus, pear, strawberry, 194 broccoli, and juices of watermelon and carrot may be useful too. Polyphenols and bioactive compounds 195 have been found to lead to significant boosting of immunity among humans [32]. Therefore, the addition 196 of polyphenol and bioactive compounds such as vitamin $C$ in the diet should be maintained to enhance 197 the immunity and decrease the vulnerability against deadly disease-causing agents such as SARS-COV-2. 198 Vitamin C may help to reduce oxidative stress and enhance the immune system. This vitamin is very 199 important in maintaining the redox balance in body tissues which is important for energy generation in 200 the cells [33]. It is believed that Vitamin C helps the immune system to fight diseases caused by bacteria and viruses and also helps to clean up the cellular mess by producing neutrophils, lymphocytes and

202 phagocytes [34]. Clinical trials have shown antioxidant supplementation specifically with Vitamin C may 203 significantly improve the immune response of elderly people [35].

\section{COVID-19 and Food security}

COVID-19 is acknowledged as a health threat that poses a challenge to food security, from both an actual and a perceptual basis. Food security exists when all people, at all times, have physical, social and economic access to sufficient, safe and nutritious food which meets their dietary needs and food preferences for active and healthy life [36]. All the four dimensions of food security viz availability, access, utilization, and stability as defined by the Food and Agriculture Organization of the United

211 Nations have fallen negatively under the stress of COVID-19 pandemic [37,38]. The COVID-19 pandemic

212 has revealed that food production, processing, and distribution systems are vulnerable. The pandemic

213 has emerged as an alarm for food security as it not only caused a restriction in movements but also 214 income losses to a greater section of the worldwide population. The pandemic has caused difficulties to 215 run agriculture smoothly, disruptions in food supply chains, and most importantly the restrictions on the 216 access of the consumers to the market for purchasing the food items. The producers are unable to get 217 seeds or fertilizer for the planting season, whereas the crops ready to harvest are threatened by a scarcity 218 of the farm labourers. The closure of markets has stopped the selling of food crops in stock. Additionally, 219 the shortage of certain ingredients required in the formulation of highly processed foods will make it difficult to produce such food items or products. Therefore, the reformulation of such food products might be required. Furthermore, climate and environmental shocks continue to threaten food supplies. (https://www.weforum.org/agenda/2020/05/what-s-needed-to-protect-food-security-during-covid-19/).

There are many hot spots pertaining to the food security in this pandemic which includes, the areas where logistics and distribution are difficult even without morbidity and social distancing. In addition, food production in some countries is affected by some other reasons such as frequent extreme 
226 weather events and pests such as the current locust's plague - the worst in decades. More than 0.8 billion people who were already chronically food insecure, the restrictions on moment and income due to Covid-19 have made them more poor and vulnerable and the increase in the cost of food import by the countries with considerable currency

depreciation

230 (https://www.worldbank.org/en/topic/agriculture/brief/food-security-and-covid-19). The structural

231 vulnerability and known food insecurity hotspots are shown in Figure 5.

232 Moreover, many other things which make the Covid-19 pandemic more critical such as nearly 21 million 233 people in western and central Africa will get food shortage due to the approaching lean season in July234 August months (https://www.weforum.org/agenda/2020/05/what-s-needed-to-protect-food-securityduring-covid-19/). The supply chain is not the same for all the food items, for example, the supply chain of fruits and vegetables and foods sold primarily by restaurants is complex than that of basic staple items such as cereal grains. As per the opinion of Mukiibi, [39], the virus is gaining more ground in the global south and food relief is just a temporary reaction to the emerging outcries and it may not stay as long as the pandemic situation normalizes. During the COVID19 pandemic, the major exporters and importers should agree to ease out the trade barriers to allow free movement of the food across the borders to minimize the chances of global food insecurity. The role of government is crucial to ensure disease-free food supply and to make sure the implementation of all SOPs in the supply chain [40]. The COVID-19 pandemic has considerably increased food insecurity across the globe. The immediate effects of the COVID-19 pandemic are amplifying the existing inequality and disproportionately affecting the lowincome, food-insecure households that were struggling to meet basic needs [41].

On the other hand the pandemic had impact on food systems due to fear of contagion, worker illness, social distancing, quarantines measures, restriction of people's movements, 'thickening' of borders and lockdown. The Food service sector (restaurants, cafés, bars, hotels, schools etc.) affected mostly by the pandemic (lost jobs, supply chains to food service may be ill-suited to supplying the food retailing sector, for example, in terms of processing capacity, packaging size and distribution infrastructure, wasting of food, for example potatoes, fresh produce, fish). Furthermore, food chain disruptions occurred due to, for example, reduced production, closure of food manufacturing industries, international trade disruptions, open market closures, labor shortages. The pandemic had also an effect on consumer behavior for example hoarding and panic-buying, reduced visits of food markets / grocery stores, price sensitiveness of consumers due to lower income, 
changed for example shift to processed foods, higher consumption of alcoholic drinks, reduction in diversification, reduction in physical activity. This could have longer-term effects on obesity and non-

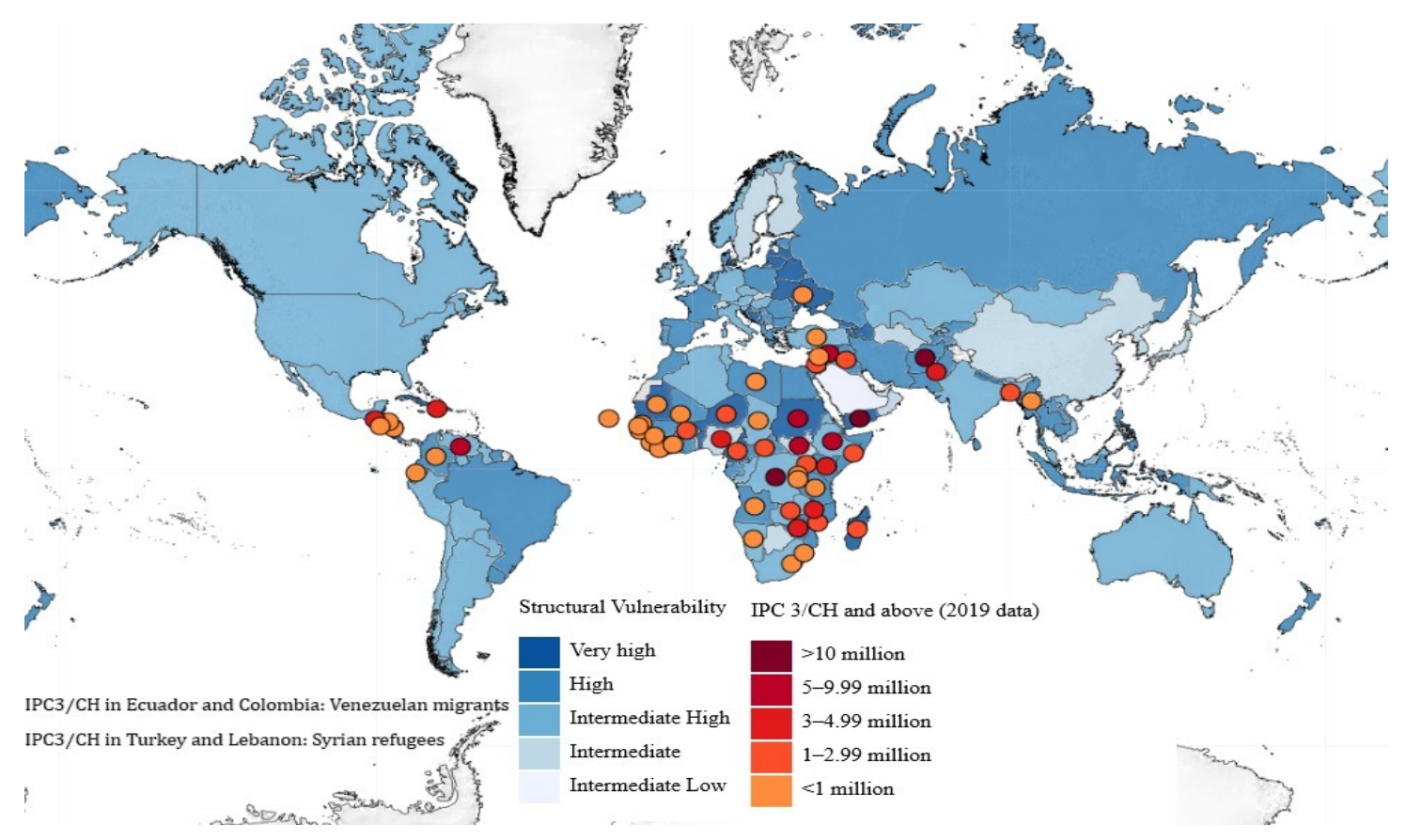

Figure 5 Structural vulnerability and known food insecurity hotspots (UNO, 2020)

\section{Conclusion}

268 The novel SARS-CoV-2 is a respiratory virus known to spread by upper respiratory secretions, including airborne droplets after coughing or sneezing. It is responsible for severe acute respiratory syndrome (SARS) coronavirus disease. Covid-19 is a deadly disease which has originated from the Wuhan city of the Hubei province of south China in late 2019 and has been declared as a pandemic by WHO. SARSCoV-2 has also been spotted in the stool of certain people, signalling towards the faecal-oral mode of transmission. However, questions remain unclear and more studies are urgently needed to explore the role of food in transmission, apparently the openly sold food items and street food vending seem to be of

275 primary concern. The SOPs like washing hands, culinary surfaces, equipment, and utensils must be 276 followed while handling food, to avoid cross-contamination and mixing. The fight against Covid-19 is not 277 limited to food safety or hygiene and sanitation only. The immunity to resist the virus needs to be boosted through diets rich in vitamins and bioactive components, thus nutrition also has a significant role 
279 to play. The COVID-19 pandemic has considerably increased food insecurity across the globe. The 280 immediate effects of the COVID-19 pandemic are amplifying the existing inequality and 281 disproportionately affecting the low-income, food-insecure households that were struggling to meet a 282 basic needs. There is a lot of information that we don't know about the novel coronavirus that has created 283 a disaster in the world. Finally, it is suggested everyone be a responsible individual, we should fight this 284 pandemic all together and take care of everyone around. 


\section{References}

[1] Burrell, C. J.; Howard, C. R.; Murphy, F. A. Fenner and White's Medical Virology. 5th Edition, Hardcover ISBN: 9780123751560 eBook ISBN: 9780123751577. Academic Press. 2017

[2] Peiris, J.S.M. Coronaviruses. Medical Microbiology (Eighteenth Edition),(pp 587-593). ISBN 978-07020-4089-4 , Imprint :Churchill Livingstone 2012

[3] Korsman, S. N., Van Zyl, G., Preiser, W., Nutt, L., \& Andersson, M. I. Human coronaviruses. Virology, (pp94-95). ISBN 978-0-443-07367-0. Imprint: Churchill Livingstone 2012

[4] Guo, Y. R., Cao, Q. D., Hong, Z. S., Tan, Y. Y., Chen, S. D., Jin, H. J., \& Yan, Y. The origin, transmission, and clinical therapies on coronavirus disease 2019 (COVID-19) outbreak-an update on the status. Military Med Research 2020, 7(1), 1-10.

[5] Giovanetti, M.; Benvenuto, D.; Angeletti, S.; Ciccozzi, M. The first two cases of 2019-nCoV in Italy: where they come from? J. Med. Vir, 2020, 1-4. https:// doi.org/10.1002/jmv.25699 [Epub ahead of print]. 10.

[6] Sims, T. Coronavirus: Healthy Habits During a Pandemic. International food information safety council foundation. 2020.

[7] World Health Organization. Coronavirus disease (COVID-2019) situation reports. 2020. https:// www.who.int/emergencies/diseases/novel-coronavirus-2019/situationreports, 2020

[8] Li, H.; Mendelsohn, E.; Zong, C.; Zhang, W.; Hagan, E.; Wang, N.; Ross, N. Human-animal interactions and bat coronavirus spillover potential among rural residents in Southern China. Biosafety and Health, 2019, 1(2), 84-90.

[9] World Health Organization. Avian influenza: food safety issues. http://www.who.int/foodsafety/micro/avian/en/index.html, 2008

[10] Bosch, A.; Pintó, R. M.; Guix, S. Foodborne viruses. Cur opin in food sci, 2016, 8, 110-119.

[11] Larkin, E. P. Food contaminants-viruses. J. food prot, 1981, 44(4), 320-325.

[12] Food and Drug Adminstration. Food Safety and the Coronavirus Disease 2019 (COVID-19) (https://www.fda.gov/food/food-safety-during-emergencies/food-safety-and-coronavirus-disease2019-covid-19, 2020

[13] Bosch, A.; Gkogka, E.; Le Guyader, F. S.; Loisy-Hamon, F.; Lee, A.; van Lieshout, L.; Winkler, A. Foodborne viruses: Detection, risk assessment, and control options in food processing. Int. j. food micro,2018, 285, 110-128.

[14] Galanakis, C. M. The Food Systems in the Era of the Coronavirus (COVID-19) Pandemic Crisis. Foods, 2020, 9(4), 523.

[15] Bidawid, S.; Malik, N.; Adegbunrin, O.; Sattar, S. A.; Farber, J. M. Norovirus cross-contamination during food handling and interruption of virus transfer by hand antisepsis: experiments with feline calicivirus as a surrogate. J. food prot, 2004, 67(1), 103-109.

[16] Pavli, A.; Tsiodras, S.; Maltezou, H. C. Middle East respiratory syndrome coronavirus (MERS$\mathrm{CoV})$ : prevention in travelers. Travel med. infec dis, 2014, 12(6), 602-608.

[17] Vasickova, P.; Pavlik, I.; Verani, M.; Carducci, A. Issues concerning survival of viruses on surfaces. Food Environ Virol,2010, 2(1), 24-34.

[18] Lyons, S. How long does coronavirus last on surfaces? https://www.abc.net.au/news/science/202003-20/how-long-does-coronavirus-last-on-surfaces/12074330, 2020

[19] Mackay, M. Why does soap work so well on SARS-CoV-2? Virology down Under. https://virologydownunder.com/why-does-soap-work-so-well-on-sars-cov-2/, 2020

[20] Wang, N.; Li, S. Y.; Yang, X. L.; Huang, H. M.; Zhang, Y. J.; Guo, H.; Hagan, E. Serological 
evidence of bat SARS-related coronavirus infection in humans, China. Virol Sinica, 2018, 33(1), 104107.

[21] Marshall, M. How soap kills the coronavirus. https://www.vox.com/2020/3/18/21185262/how-soapkills-the-coronavirus, 2020

[22] Henwood, A.F. Coronavirus disinfection in histopathology. J. Histotechnology, 2020, 1-3.

[23] Eslami, H.; Jalili, M. The role of environmental factors to transmission of SARS-CoV-2 (COVID-19). AMB Express, 2020, 10(1), 1-8.

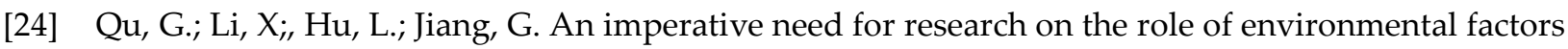
in transmission of novel Coronavirus (COVID-19). Environ Sci \& Technol, 2020, 54:3730-3732. https://doi.org/10.1021/acs.est.0c011 02

[25] Randazzo, W.; Truchado, P.; Ferrando, E. C.; Simon, P.; Allende, A.; Sanchez, G. SARS-CoV-2 RNA titers in wastewater anticipated COVID-19 occurrence in a low prevalence area. medRxiv, 2020

[26] Bhattacharjee, S. Statistical investigation of relationship between spread of coronavirus disease (COVID-19) and environmental factors based on study of four mostly afected places of China and fve mostly afected places of Italy. arXiv preprint, 2020, arXiv:2003.11277

[27] Gale, J. Fecal transmission may be responsible for coronavirus's rapid spread. Fortune, https://fortune.com/2020/02/20/coronavirus-fecal-transmission/, 2020

[28] Rasmussen, S. A.; Smulian, J. C.; Lednicky, J. A.; Wen, T. S.; Jamieson, D. J. Coronavirus Disease 2019 (COVID-19) and Pregnancy: What obstetricians need to know. Am. J. obst and gynecol, 2020, 222(5), 415-426.

[29] Knutson, K. L.; von Schantz, M. Associations between chronotype, morbidity and mortality in the UK Biobank cohort. Chronobiology inter, 2018,35(8), 1045-1053.

[30] Peake, J.; Suzuki, K. Neutrophil activation, antioxidant supplements and exercise-induced oxidative stress. Exer Immunol Review, 2004, 10(1), 129-141.

[31] Segerstrom, S. C.; Miller, G. E. Psychological stress and the human immune system: a metaanalytic study of 30 years of inquiry. Psychol bulletin, 2004, 130(4), 601.

[32] Basiri, M. R. Theory about Treatments and Morbidity Prevention of Corona Virus Disease (Covid19). J.Phar. Pharmacol, 2020, 8, 89-90.

[33] Cheng, L.; Zheng, W.; Li, M.; Huang, J.; Bao, S.; Xu, Q.; Ma, Z. Citrus fruits are rich in flavonoids for immunoregulation and potential targeting ACE2. 2020, Preprints.

[34] Collins, C. (2020) http://the conversation .com

[35] Bendich, A. Physiological role of antioxidants in the immune system. J. Dairy Sci, 1993, 76(9), 27892794.

[36] Food and Agriculture Organization . Food security policy brief. 2006, 2

[37] Zurayk, R. Pandemic and Food Security. J. Agri, Food Sys, and Community Dev, 2020, 9(3), 1-5.

[38] United Nations Organization. The impact of COVID-19 on food Security and Nutrition. www.un.org., 2020

[39] Mukiibi, E. COVID-19 and the state of food security in Africa. Agric and Human Values,2020, 1.

[40] Glauber, J. O. S. E. P. H.; Laborde, D. A. V. I. D.; Martin, W. I. L. L.; Vos, R. COVID-19: Trade restrictions are worst possible response to safeguard food security. Inter Food Policy Res Institute, 2020, 27.

[41] Wolfson, J. A.; Leung, C. W. Food Insecurity and COVID-19: Disparities in Early Effects for US Adults. Nutrients, 2020, 12(6), 1648. 
